\title{
Economic policy uncertainty and volatility of treasury futures
}

\author{
Maojun Zhang ${ }^{1}\left[\right.$. Yang Zhao ${ }^{1}$. Jiangxia Nan ${ }^{1}$
}

Accepted: 9 July 2021 / Published online: 3 September 2021

(c) The Author(s), under exclusive licence to Springer Science+Business Media, LLC, part of Springer Nature 2021

\begin{abstract}
This paper investigates the relation between Treasury futures market volatility and economic policy uncertainty using GARCH-MIDAS. We formulated models with the realized volatility of Treasury futures, the level and volatility of economic policy uncertainty. We find that the realized volatility of Treasury futures and economic policy uncertainty play a significant role in the dynamics of long-run volatility in Treasury futures markets in China and United States.
\end{abstract}

Keywords Economic policy uncertainty $\cdot$ Treasury futures · Volatility $\cdot$ Mixed frequency regression

\section{Introduction}

A well-functioning government Treasury market is the linchpin for the development of any capital market, and sovereign bonds are used as a risk-free benchmark for other fixed income securities. Chinese government bonds account for about 20 percent of the domestic bond market, with maturities ranging from 3 months to 50 years. By the end of 2020, the issued bonds worth 104.32 trillion Yuan, up 19.38\% year-on-year, where the government issued bond is 45.6 trillion Yuan. The China Financial Futures Exchange launched 5-year Treasury futures in September 2013, 10-year Treasury futures in March 2015, and 2-year Treasury futures in August 2018, providing diversified tools for managing interest rate risks. All three products

Maojun Zhang

2721@mail.usts.edu.cn

Yang Zhao

zhaoyang@mail.usts.edu.cn

Jiangxia Nan

jiangxia1107@163.com

1 School of Business, Suzhou University of Science and Technology, Xuefu Road 99, Huqiu

District, Suzhou 215009, Jiangsu Province, China 
are physically settled, and each has a set of bonds (a basket) used for settlement with specified coupon rates and deliverable maturities. The deliverable bonds for 5-year Treasury futures are book-entry interest-bearing Treasury bonds with an original maturity of no more than 7 years and a remaining maturity of 4 years to 5.25 years upon the first day of the expiry month. Ten-year Treasury futures have an original maturity of no more than 10 years and a remaining maturity of no less than 6.5 years upon the first day of the expiry month. Two-year Treasury futures have an original maturity of no more than 5 years and a remaining maturity of 1.5 years to 2.25 years upon the first day of the expiry month. According to the data from China Financial Futures Exchange, the scale of Treasury futures has grown rapidly since 2013. The total value of the Treasury futures at the end of 2019 is 147593 billion Yuan, which is 40.64 times of 3.632 billion Yuan at the end of 2013. However, compared with the size of Treasury bonds in the spot market, the Treasury futures market is still very small.

The price discovery function of Treasury futures can effectively predict the reasonable price of Treasury bond (Brandt et al., 2007; Man et al., 2013). In addition, Treasury futures can hedge Treasury spot price risk. The volatility of Treasury futures price is an important factor in Treasury pricing and risk management (Cox and Mitchell, 1993). It is influenced by macroeconomic factors such as GDP, PPI, CPI and employment rate. For example, Ederington and Lee (1993) analyzed the impact of macroeconomics on the high-frequency volatility of long-term Treasury futures, and Shi et al. (2009) analyzed the impact of macroeconomics on the volatility of Japanese government bond futures. Further, Orlowski (2015) found that electronic trading mechanism significantly reduced the price volatility of US Treasury futures. Park et al. (2017) analyzed the impact of foreign investors' participation on the price volatility of Korean Treasury futures. Therefore, the price volatility of Treasury futures is affected by the economic policy and trading mechanism among other factors.

The impact of policy risk on the market is growing and economic policy decisions influence economic activity. Uncertainty pertaining to economic policy decisions, regardless of its origin (whether from fiscal or monetary policy decisions), will discourage investor confidence and firms from investing, and thus, have a profound impact on bond markets. Many prior studies emphasize the importance of uncertainty in economic policy. Baker et al. (2016) constructed an economic policy uncertainty (abbreviated as EPU) index to measure the uncertainty related to monetary, fiscal, and other relevant policies; the study showed that the EPU index influences the intensity of the business cycle and investment. Many scholars began to use the index to measure economic policy uncertainty and study its impact on the stock market, enterprise investment and other microeconomic phenomena. For example, Jonathan and Andrew (2015) studied the impact of economic policy uncertainty on the stock markets of the US. Gulen and Ion (2016) analyzed the impact of economic policy uncertainty in the United States on the investment of American enterprises.

Moreover, the uncertainty of economic policy is the leading mechanism of macroeconomic changes, which can describe the changes of monetary policy, fiscal policy, issuance, supervision, trading and so on. EPU refers to the fact that economic entities cannot accurately predict whether, when, and how the government will 
change the current economic policies Baker et al. (2016). It has been widely recognized that EPU has a significant impact on the bond market in the US (Wisniewski and Lambe, 2015; Fang et al.,2017). In the process of arbitrage trading of Treasury futures, information and capital are interactively transferred between the futures and the spot market, and jointly affect the return and risk of Treasury futures and spot market. The characteristics of the information transmission between the U.S. Treasury futures and spot markets in different periods are found (Hung and Zhang 1995; Brandt and Kavajecz, 2004 and 2007; Mizrach and Neely, 2008). Since Regulators' supervision of Treasury futures market and investors' prediction of Treasury futures prices are highly dependent on the economic policies of the government, the uncertainty of economic policies is an important source of the uncertainty of the external environment of Treasury futures. The academic research on the measurement and influence of the uncertainty of the economic policy are in the ascendant, which provides a valuable reference for the study of the impact of economic policy uncertainty on the price volatility of Treasury futures.

The ARCH and GARCH models proposed by Engle (1982) and Bollerslev (1986) are effective methods to depict the volatility of Treasury futures. Engle and Rangel (2008) proposed the Spline-GARCH model with multi-component structure and stated that the inflation rate and the short-term yield rate were the main drivers of the stock market volatility. These volatility models are only applicable to the same frequency explanatory variables and cannot handle the case of different frequency explanatory variables. For this reason, Engle et al. (2013), combined with the mixed frequency data sampling (MIDAS) technique proposed by Ghysels et al. (2006, 2007) established the GARCH-MIDAS model, which divided the daily volatility of assets into the product of the long-term and the short-term components. The shortterm component is a GARCH model, and the long-term one can be characterized by the low-frequency macroeconomic variable or the actual volatility. The GARCHMIDAS model mainly has the following advantages: First, data of different frequencies can be added to the model for analysis to minimize the information loss of high-frequency data in the frequency reduction process, and reduce the noise impact carried by high-frequency data as well as avoid the problem of too many parameters in the high-frequency data processing. Second, when the return and volatility of low-frequency macroeconomic factors are used as explanatory variables, whether they are stable or not, can be ignored. Thirdly, the measurement of daily volatility with long-term components can not only fully extract information of low-frequency data but also filter the influence of intraday instant information (short-term components), which means that the mixed frequency fluctuation model can describe the long-term and short-term fluctuation characteristics of Treasury futures price in a more detail.

In addition, from the perspective of data analysis, the data of EPU is monthly while that of Treasury futures is daily. As the GARCH-MIDAS model is an efficient tool in dealing with mixing volatility model, this paper constructs a GARCHMIDAS model to investigate the impact of economic policy uncertainty on the volatility of Treasury futures in the United States and China. The realized volatility of Treasury futures, the level and volatility of EPU are three explanatory factors. The main contribution and innovation of this paper are as follows. We use a 
GARCH-MIDAS approach to link economic policy uncertainty to the long-term component of volatility in the Treasury futures market. We also find the long-run volatility of Treasury futures market is positively correlated with the past realized volatility of Treasury futures, the change and volatility of EPU. It implies that the past realized volatility and EPU play a key role in the dynamics of long-run volatility in Treasury futures markets.

The rest of the paper is organized as follows. Section 2 describes the GARCHMIDAS models for Treasury futures and EPU. Section 3 shows the data and its basic statistical description. Section 4 discusses the empirical findings and further analysis. We conclude in Section 5.

\section{GARCH-MIDAS model}

The GARCH-MIDAS model not only takes low-frequency variables as explanatory factors but also distinguish short-run from long-run volatility. The short-term component is a mean reversion while the long-term component is composed of the realized volatility of Treasury futures or EPU weighted by MIDAS polynomials. This section briefly reviews GARCH-MIDAS models proposed by Engle et al. (2013).

\subsection{Models with realized volatility of treasury futures}

We consider a return of Treasury futures for day $i$ in month $t$ with $N_{t}$ days, which may vary with the time and is written as

$$
r_{i t}=\mu+\sqrt{\tau_{t} \times g_{i t}} \varepsilon_{i t}, \forall i=1,2, \cdots, N_{t}
$$

where $\varepsilon_{i t} \mid \Phi_{i-1, t} \sim N(0,1)$ with $\Phi_{i-1, t}$ is the information set up to day $(i-1)$ of month $t, N(0,1)$ is the standard normal distribution function and $\mu=\mathrm{E}_{i-1, t}\left(r_{i t}\right)$ represents the conditional mean of the return $r_{i t}$. The $\tau_{t}$ and $g_{i t}$ represent long-term and shortterm component of the conditional variance of the return $r_{i t}$, respectively. Moreover, denote $h_{t}=\operatorname{Var}\left(r_{i t}\right)$ be the conditional variance of the return $r_{i t}$, which satisfies $h_{t}=g_{i t} \times \tau_{t}$. Assume that volatility dynamics of the short-term component $g_{i t}$ is a daily $\operatorname{GARCH}(1,1)$ process (see Engle et al. (2013)):

$$
g_{i t}=(1-\alpha-\beta)+\alpha \frac{\left(r_{i-1, t}-\mu\right)^{2}}{\tau_{t}}+\beta g_{i-1, t}
$$

where $\alpha$ and $\beta$ are parameters satisfying $\alpha+\beta<1$.

Furthermore, consider monthly realized volatility of the return $r_{i t}$, denoted by $R V_{t}$ at month $t$ for the fixed time span case as follows

$$
R V_{t}=\sum_{i=1}^{N_{t}} r_{i t}^{2}
$$


Next, we consider a rolling window specification for the MIDAS filter. Namely, we remove the restriction that $\tau_{t}$ is fixed for month $\mathrm{t}$, which makes $\tau$ and $g$ both change at the daily frequency. So, the realized volatility of the return for a rolling window can be defined as

$$
R V_{t}^{(r w)}=\sum_{i=1}^{N_{t}^{\prime}} r_{t-i}^{2}
$$

where $r_{t-i}$ indicate that we roll back the days across various periods $t$ without keep track of it. When $N^{\prime}=22$, we call it monthly rolling window RV.

We also consider the log version of long-term component $\tau_{t}$ for the fixed time span case, which can be expressed as

$$
\log \tau_{t}=m+\theta \sum_{k=1}^{K} \varphi_{k}\left(\omega_{1}, \omega_{2}\right) R V_{t-k}
$$

where $m$ and $\theta$ are parameters, $K$ represents the maximum lag order of realized volatility $R V_{t-k}$. And let $\varphi_{k}\left(\omega_{1}, \omega_{2}\right)$ be a weight Beta function, denoted by

$$
\varphi_{k}\left(\omega_{1}, \omega_{2}\right)=\frac{(k / K)^{\omega_{1}-1}(1-k / K)^{\omega_{2}-1}}{\sum_{k=1}^{K}(k / K)^{\omega_{1}-1}(1-k / K)^{\omega_{2}-1}}
$$

where $\omega_{1}$ and $\omega_{2}$ are the variables of the weight function. And its rolling sample counterpart is defined similarly.

The Eqs. (1), (2), (3), (4), (5) and (6) constitute the GARCH-MIDAS model based on the realized volatility. when $\theta$ is positive, it means that the realized volatility is positively correlated with the long-term component of Treasury futures volatility. When $\theta$ is negative, it means that the realized volatility is negatively correlated with the long-term component of Treasury futures volatility. The class of GARCH-MIDAS models involving realized volatility were based on one-sided MIDAS filters.

In order to estimate volatility of monthly economic policy uncertainty series, we follow the approach taken by Schwert (1989) to fit the autoregressive model to estimate the monthly volatility of EPU. The autoregressive model AR (12) of EPU is presented below

$$
E P U_{v, t}^{y}=\alpha+\sum_{j=1}^{12} \beta_{j} E P U_{v, t-\mathrm{j}}^{y}+\varepsilon_{t}
$$

where the lag 12 is used to indicate the monthly data of EPU. The square of the residual term of AR (12) is used as the volatility of EPU, which reason is come from the Engle et al. (2013) who use the square of the residual term to estimate macroeconomic volatility. 


\subsection{Models with economic policy uncertainty}

In this section, we turn to GARCH-MIDAS models with one-sided filters, involving EPU variable. If a level value of the economic policy uncertainty EPU is used as a factor of the log long-term component, which is expressed as

$$
\log \tau_{t}=m_{l}+\theta \sum_{k=1}^{K_{l}} \varphi_{k}\left(\omega_{1}, \omega_{2}\right) E P U_{l, t-k}^{y}
$$

where $E P U_{l, t}^{y}$ is a level value, $m_{l}$ is a parameter and $K_{l}$ represents the maximum lag order of the level value. When $\theta$ is positive, it means that the level value of the EPU is positively correlated with the long-term component of Treasury futures volatility. When $\theta$ is negative, it means that the level value of the EPU is negatively correlated with the long-term component of Treasury futures volatility. If the volatility of EPU is used as a factor of the log long-term component:

$$
\log \tau_{t}=m_{v}+\theta \sum_{k=1}^{K_{v}} \varphi_{k}\left(\omega_{1}, \omega_{2}\right) E P U_{v, t-k}^{y}
$$

where $E P U_{v, t-k}^{y}$ is a volatility of EPU, $m_{v}$ is the parameter and $K_{v}$ represents the maximum lag order of the volatility. When $\theta$ is positive, it indicates that the volatility of economic policy uncertainty is positively correlated with the long-term component of Treasury futures volatility. When $\theta$ is negative, it indicates that the volatility of EPU is negatively correlated with the long-term component of Treasury futures.

We also consider a model that combines the level and volatility of EPU:

$$
\log \tau_{t}=m_{l v}+\theta_{l} \sum_{k=1}^{K_{l}} \varphi_{k}\left(\omega_{1, l}, \omega_{2, l}\right) E P U_{l, t-k}^{y}+\theta_{v} \sum_{k=1}^{K_{v}} \varphi_{k}\left(\omega_{1, v}, \omega_{2, v}\right) E P U_{v, t-k}^{y}
$$

How much the expected volatility of Treasury futures can be explained by EPU? To answer this question we use the variance ratios below

$$
\frac{\operatorname{Var}\left(\log \left(\tau_{t}^{[M]}\right)\right.}{\operatorname{Var}\left(\log \left(\tau_{t}^{[M]} g_{t}^{[M]}\right)\right.}
$$

where $\mathrm{M}$ refers to a specific model: GARCH-MIDAS with rolling window RV, with fixed span RV, with level and variance.

\section{Data}

We now obtain daily prices of 5-year Treasury futures with an underlying Treasury with 5 -year maturity in China, denoted by C5TF, and daily prices of 10-year Treasury futures with an underlying Treasury of 10-year maturity in United States, denoted by US10TF. The data are from the Wind dataset. To measure the 
Table 1 Summary statistics for variables

\begin{tabular}{|c|c|c|c|c|c|c|c|}
\hline Variable & Sample & Mean & $\mathrm{SD}$ & $\operatorname{Max}$ & Min & Skewness & Kurtosis \\
\hline \multicolumn{8}{|c|}{ 5-year Treasury Futures of China } \\
\hline Return & 1906 & 0.003 & 0.21 & 1.94 & -1.35 & 0.32 & 11.17 \\
\hline $\mathrm{RV}$ & 90 & 0.88 & 0.97 & 5.20 & 0.06 & 2.32 & 8.84 \\
\hline Level & 90 & 0.08 & 0.40 & 1.47 & -0.57 & 0.83 & 4.22 \\
\hline Volatility & 90 & 0.13 & 0.21 & 1.07 & 0.00 & 2.84 & 11.35 \\
\hline \multicolumn{8}{|c|}{ 10-year Treasury Futures of U.S. } \\
\hline Return & 1906 & 0.003 & 0.30 & 1.62 & -1.83 & -0.11 & 6.15 \\
\hline $\mathrm{RV}$ & 90 & 1.83 & 1.92 & 17.04 & 0.30 & 5.85 & 45.63 \\
\hline Level & 90 & 0.058 & 0.35 & 1.43 & -0.60 & 1.33 & 6.29 \\
\hline Volatility & 90 & 0.103 & 0.23 & 1.49 & 0.00 & 4.79 & 26.81 \\
\hline
\end{tabular}

These variables are the daily return and realized variance of Treasury futures, monthly level and volatility of economic policy uncertainty. The sample covers from September 2013 to March 2021

uncertainty of economic policy, we use the EPU index constructed by Baker et al. (2016). We also use the monthly U.S. economic policy uncertainty (USEPU) index and monthly Chinese economic policy uncertainty (CEPU). The sample range is from September 2013 to March 2021 including COVID-19 late periods.

Figure 1 shows the trend of EPU and Treasury futures for C5TF in above panel and US10TF in below panel, respectively. Roughly, EPU and Treasury futures tend to move in the same direction, especially since late 2019 when the COVID19 broke out and the EPU is rapidly increasing. According to this figure we see that, in general, an increase (decrease) in economic policy uncertainty leads to a very short-up (drop) in the price of Treasury futures.

Table 1 provides the summary statistics of the daily log return and realized volatility of Treasury futures, the level and volatility of EPU in China and United States, respectively. To appreciate the time series pattern of the series which enter our models, Figure 2 shows plots of the level and realized variance of CEPU and USEPU used in the GARCH-MIDAS specification. As far as the levels and realized variance go, we note remarkable changes across time and a few times under the issue of structural breaks. The former shows economic policy uncertainty level variables with structural breakpoints around 2015 for CEPU and 2017 for USEPU, whereas the latter shows economic policy uncertainty volatility variables with remarkable changes around 2016 for CEPU and 2017 for USEPU.

\section{Empirical analysis}

According to the GARCH-MIDAS models in Section 2, we analyze the parameter estimates obtained by The MIDASv2.3 package of MATLAB software. 
Table 2 Parameter estimates of GARCH-MIDAS with realized variance

\begin{tabular}{llcccccccc}
\hline Treasury futures & Regressor & $\mu$ & $\alpha$ & $\beta$ & $\theta$ & $\omega$ & $m$ & LLF \\
\hline C5TF & Fixed RV & 2.74 & $0.07^{* * *}$ & $0.93^{* * *}$ & $0.10^{* * * *}$ & $4.99^{* * * *}$ & 0.01 & 429.97 \\
& & $(0.96)$ & $(13.39)$ & $(204.80)$ & $(13.53)$ & $(4.58)$ & $(0.34)$ & \\
& \multirow{2}{*}{ Rolling RV } & 2.84 & $0.05^{* * *}$ & $0.90^{* * *}$ & $0.10^{* * *}$ & $5.00^{* * *}$ & $0.01^{* * *}$ & 259.18 \\
& & $(1.48)$ & $(20.00)$ & $(222.450)$ & $(25.44)$ & $(6.94)$ & $(0.79)$ & \\
US10TF & Fixed RV & 0.86 & $0.07^{* * *}$ & $0.93^{* * *}$ & $0.10^{* * *}$ & $4.98^{* * *}$ & 0.01 & -296.15 \\
& & $(0.18)$ & $(12.72)$ & $(164.62)$ & $(5.55)$ & $(3.94)$ & $(0.08)$ & \\
& \multirow{2}{*}{ Rolling RV } & 1.32 & $0.07^{* * *}$ & $0.93^{* * *}$ & $0.10^{* * *}$ & $4.99^{* * *}$ & 0.01 & -285.48 \\
& & $(0.28)$ & $(11.99)$ & $(157.59)$ & $(5.32)$ & $(3.33)$ & $(0.06)$ & \\
\hline
\end{tabular}

GARCH-MIDAS models with the fixed realized variance in Eq. (3) and the rolling realized variance in Eq. (4) are fitted via Log-likelihood function. The model specification has different interpretations for GARCH-MIDAS model with fixed span RV and the one with rolling window RV. The $\omega$ in the table is $\omega_{2}$ as the optimal $\omega_{1}$ in Eq. (6) is 1 such that the optimal weights are monotonically decreasing over the lags. LLF is the optimal log-likelihood function value. The numbers in the parenthesis are t-stats computed with HAC standard errors

The *** indicates significance at $1 \%$ level

\subsection{Estimation of GARCH-MIDAS with realized variance}

As was mentioned in the previous section, there are two variations of GARCHMIDAS models with RV: GARCH-MIDAS with fixed span in Eqs. (3) and (5), rolling window RV in Eqs. (4) and (5). In case of fixed span RV, $t$ in Eq. (3) can be a month. On the other hand, for the rolling window RV, we can change $N^{\prime}$ in Eq. (4). Finally, in each case we have parameter estimates in Table 2 for C5TF and US10TF by the log-likelihood function given by (Engle et al. 2013). The most interesting parameters are the slope parameters $\theta$ shown in the first six columns of Table 2 . The results in the table show that almost all parameters are significant. Most of all for most of them, the slope $\theta$ is strongly significant and positive. This means that the realized volatility of Treasury futures is positively correlated with the long-term volatility component of Treasury futures for C5TF and US10TF.

Figure 3 shows the volatility components of GARCH-MIDAS with fixed span $\mathrm{RV}$ and rolling window RV, respectively. We notice that these conditional volatility and secular components clearly follow a similar trend, while the long-term component is much smoother.

\subsection{Estimation of GARCH-MIDAS with economic policy uncertainty}

In this subsection we start with the GARCH-MIDAS models involving either the level in Eq. (8) or volatility in Eq. (9) of EPU. We focus first on the one-sided filters. The parameter estimates appear in Table 3 for C5TF and US10TF. The most interesting parameter is the slope parameters for level/volatility specifications of the MIDAS filter. Consider first the parameter estimates for level of CEPU. The parameter estimate is 2.85 with a t-statistic of 2.92 . We find that a one percent 
increase of change in CEPU would increase the long-term component of the Chinese Treasury futures market volatility. Of course, there is a similar positive relation between the level of USEPU and Treasury futures market volatility in United States. Next, we can turn to the lower panel of Table 3, which covers the volatility of EPU. We find that the volatility of EPU has a significant positive impact on the long-term volatility of the Chinese Treasury futures market and the United States Treasury futures market.

It is also worth examining some plots of sample paths. Figure 4 presents timeseries plot of volatility components of the one-sided EPU GARCH-MIDAS models with level/volatility for C5TF and US10TF. We can see that the conditional volatility and secular components clearly follow a similar trend for either level or volatility for C5TF or US10TF. We also notice that there are significant deviations between the conditional volatility and long-term components of C5TF after abound 2016, which cause the goodness of fit of the GARCH-MIDAS-EPU model to be poor.

The parameter estimates of the model which combines level and volatility of economic policy uncertainty, namely models described by Eq. (10) appear in Table 4. In Chinese and United States cases we observe that slope parameters of level and variance are over 0.02 at the statistical significance of $10 \%$ level. This suggests that there is an evidence of co-linearity between the long-term volatility of Treasury futures and the combined level/volatility of economic policy uncertainty.

\subsection{Measuring the contribution of EPU}

We now consider the contribution of EPU to the long-term volatility of Treasury futures using the variance ratio in Eq. (11). The variance ratio results appear in Table 5, where we cover GARCH-MIDAS with rolling window RV, with fixed span RV, and with level and volatility of EPU. The sample estimates of Chinese 5-year Treasury futures tell us that the GARCH-MIDAS model with rolling RV has the most important long run component contribution-over $65 \%$, that of United States 10-year Treasury futures with fixed span RV is $42.1 \%$. Among the models involving EPU series we observe that the level model contributes to more than $17 \%$ to the total volatility in the Chinese samples or United States samples. While the variance model contributes to over $15 \%$ to the total volatility in United States samples, which is more than that of the Chinese samples, i.e. $1.41 \%$. If we combine level and variance of EPU into one model, it is surprising that we see the largest contribution-over $44 \%$ and over $22 \%$ for Chines Treasury futures and United States, respectively. The results show that the combing level and variance of EPU is clearly a great source of Treasury futures volatility. 
Table 3 Parameter Estimates of One-sided GARCH-MIDAS with EPU

\begin{tabular}{llcclllll}
\hline Treasury futures & Regressor & $\mu$ & $\alpha$ & $\beta$ & $\theta$ & $\omega$ & $m$ & LLF \\
\hline C5TF & Level & 3.30 & $0.05^{* * *}$ & $0.94^{* * *}$ & $2.85^{* * *}$ & $3.93^{* * *}$ & $-3.27^{* * * *}$ & 488.79 \\
& & $(0.79)$ & $(8.95)$ & $(158.99)$ & $(2.92)$ & $(2.87)$ & $(-14.19)$ & \\
& \multirow{2}{*}{ Volatility } & 3.49 & $0.06^{* * *}$ & $0.94^{* * *}$ & $0.45^{*}$ & 49.99 & $-2.65^{* * *}$ & 476.31 \\
& & $(0.83)$ & $(11.00)$ & $(172.30)$ & $(1.83)$ & $(0.09)$ & $(-11.42)$ & \\
\multirow{2}{*}{ US10TF } & \multirow{2}{*}{ Level } & 0.06 & $0.09^{* * *}$ & $0.85^{* * *}$ & $0.77^{* * *}$ & 29.61 & $-2.55^{* * *}$ & -213.24 \\
& & $(0.01)$ & $(6.64)$ & $(36.40)$ & $(3.32)$ & $(0.74)$ & $(0.74)$ & \\
& \multirow{2}{*}{ Volatility } & 0.20 & $0.10^{* * *}$ & $0.84^{* * *}$ & $0.96^{* *}$ & 49.98 & $-2.59^{* * *}$ & -214.12 \\
& & $(0.03)$ & $(6.81)$ & $(37.13)$ & $(2.51)$ & $(0.13)$ & $(-29.49)$ & \\
\hline
\end{tabular}

GARCH-MIDAS models with the level in Eq. (8) and the volatility Eq. (9) are fitted via Log-likelihood function. The corresponding volatility is estimated from Eq. (7). LLF is the optimal log-likelihood function value. The numbers in the parenthesis are t-stats computed with HAC standard errors

The $* * *$ and $* *$ indicates significance at $1 \%$ level, $5 \%$ level, respectively

Table 4 Parameter estimates of GARCH-MIDAS with level and volatility combined

\begin{tabular}{lllllllllll}
\hline Treasury futures & $\mu$ & $\alpha$ & $\beta$ & $\theta_{l}$ & $\theta_{v}$ & $\omega_{\mathrm{v}}$ & $\omega_{l}$ & $m$ & LLF \\
\hline C5TF & $-4.96^{*}$ & $0.13^{* * *}$ & $0.87^{* * *}$ & $0.03^{* * *}$ & $0.02^{*}$ & $11.74^{* * *}$ & 9.55 & $-4.29^{* * *}$ & 398.61 \\
& $(-1.87)$ & $(29.04)$ & $(200.07)$ & $(7.21)$ & $(1.78)$ & $(6.50)$ & $(1.32)$ & $(-24.11)$ & \\
US10TF & 0.05 & $0.09^{* * *}$ & $0.85^{* * *}$ & $0.04^{*}$ & $0.09^{*}$ & 35.17 & 23.19 & $0.07^{* * *}$ & -212.07 \\
& $(0.01)$ & $(6.58)$ & $(37.25)$ & $(1.64)$ & $(1.66)$ & $(0.32)$ & $(0.69)$ & $(10.08)$ & \\
\hline
\end{tabular}

GARCH-MIDAS models with level and volatility combined in Eq. (10) are fitted via Log-likelihood function. LLF is the optimal log-likelihood function value. The numbers in the parenthesis are t-stats computed with HAC standard errors

The $* * *, * *$ and $*$ indicates significance at $1 \%$ level, $5 \%$ level and $10 \%$ level, respectively

\section{Conclusion}

In this paper, we investigate how EPU influences the long-term volatility of Treasury futures market by employing the GARCH-MIDAS models proposed by Engle et al. (2013). We consider the Chinese 5-year Treasury futures and US 10-year Treasury futures using two different EPU indexes from Baker et al. (2016). The main empirical findings of the current study can be summarized as follows. First, there are significant causal-flows from EPU to the Treasury futures volatilities over the entire sample period from September 2013 to March 2021 including COVID-19 late periods. Second, we find that the economic policy uncertainty index has a significant positive impact on long-term volatilities of Treasury futures. Third, combing level and variance of EPU is clearly a great source of Treasury futures volatilities.

This paper contributes to the existing limited literature on the predictive ability of Treasury futures volatility through economic uncertainty using the novel technique of $\mathrm{n}$ mixed frequency regression. A probable reason for these results is that when economic policies are more uncertain, investors' effective risk 
Table 5 Summary table for variance ratios

\begin{tabular}{lcl}
\hline Model & C5TF (\%) & US10TF (\%) \\
\hline GM with fix span RV & 56.72 & 43.00 \\
GM with rolling window RV & 65.53 & 42.10 \\
GM with EPU & & \\
EPU level & 17.42 & 17.91 \\
EPU variance & 1.41 & 15.85 \\
EPU level +variance & 44.69 & 22.24 \\
\hline
\end{tabular}

The variance ratios is calculated by the Eq. (11) for GARCHMIDAS with rolling window RV, with fixed span RV, with level and variance of the EPU. GARCH-MIDAS models with level and volatility combined in Eq. (10) are fitted via Log-likelihood function. LLF is the optimal log-likelihood function value. The numbers in the parenthesis are t-stats computed with HAC standard errors

The $* * *, * *$ and $*$ indicates significance at $1 \%$ level, $5 \%$ level and $10 \%$ level, respectively

aversion increase. There is a "flight-to-quality effect". The results infer that EPU better predict the volatility of Treasury futures markets and thus have important implications for asset pricing and investment risk management decisions.

\section{Appendix}

See Fig. 1

These figures show the index of economic policy uncertainty and the price of Treasury futures. CEPU and USEPU represent economic policy uncertainty in China and economic policy uncertainty in United States, respectively.
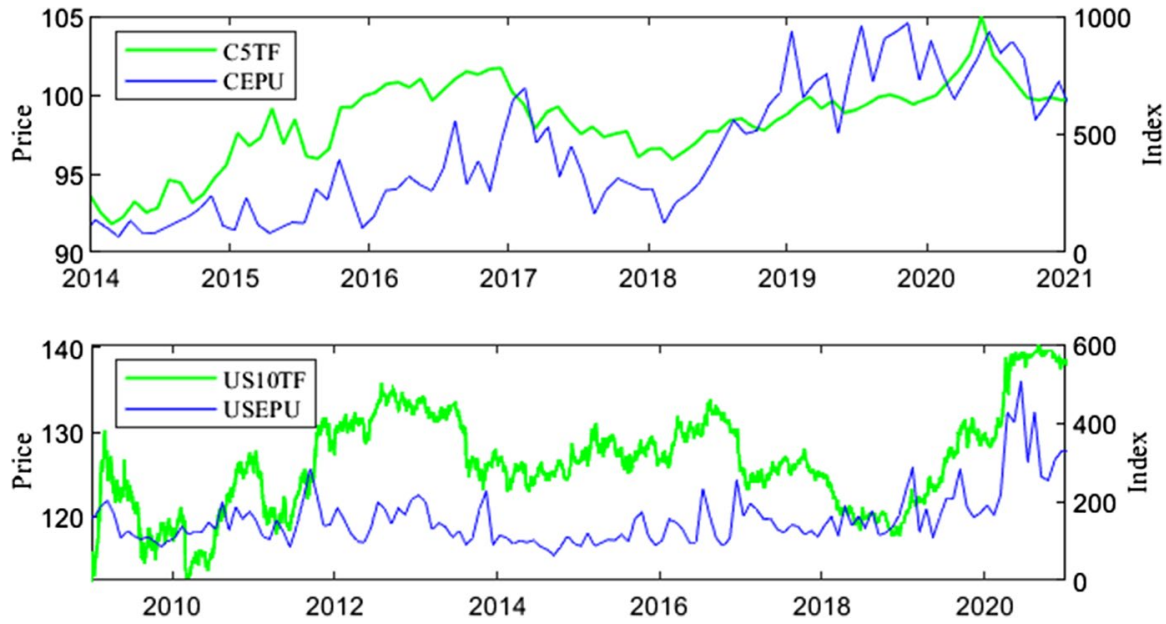

Fig. 1 Economic policy uncertainty and treasury futures 


\section{CEPU}
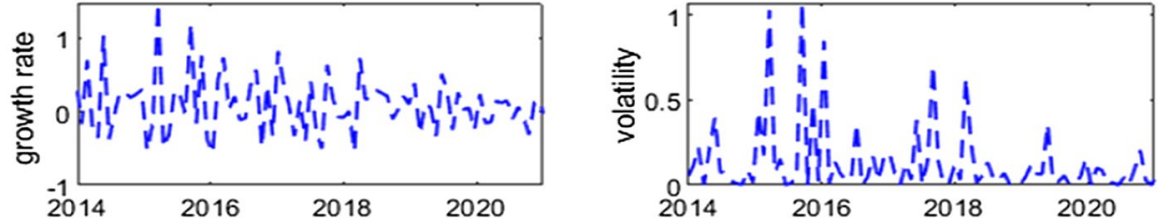

\section{USEPU}
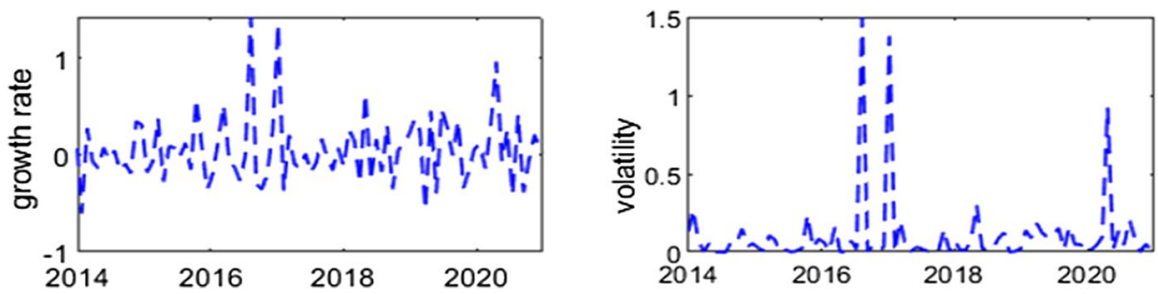

Fig. 2 Economic policy uncertainty level variables and realized volatility
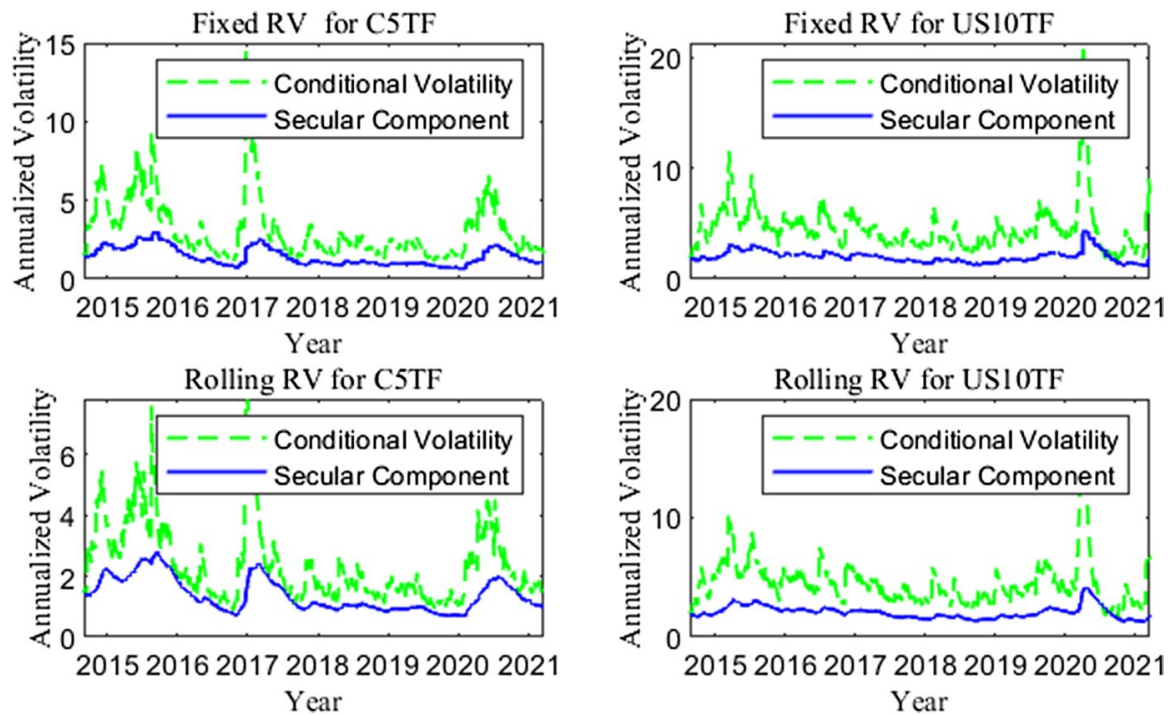

Fig. 3 GARCH-MIDAS with fixed span rv and rolling window RV

See Fig. 2

These figures show the level and realized variance of economic policy uncertainty. The growth rate and volatility represent the level and realized variance

of economic policy uncertainty, respectively.

See Fig. 3

The figure shows the estimated conditional volatility and its long run component of GARCH-MIDAS model with fixed RV and rolling window for C5TF and US10TF. The corresponding parameter estimates are shown in Table 2. 

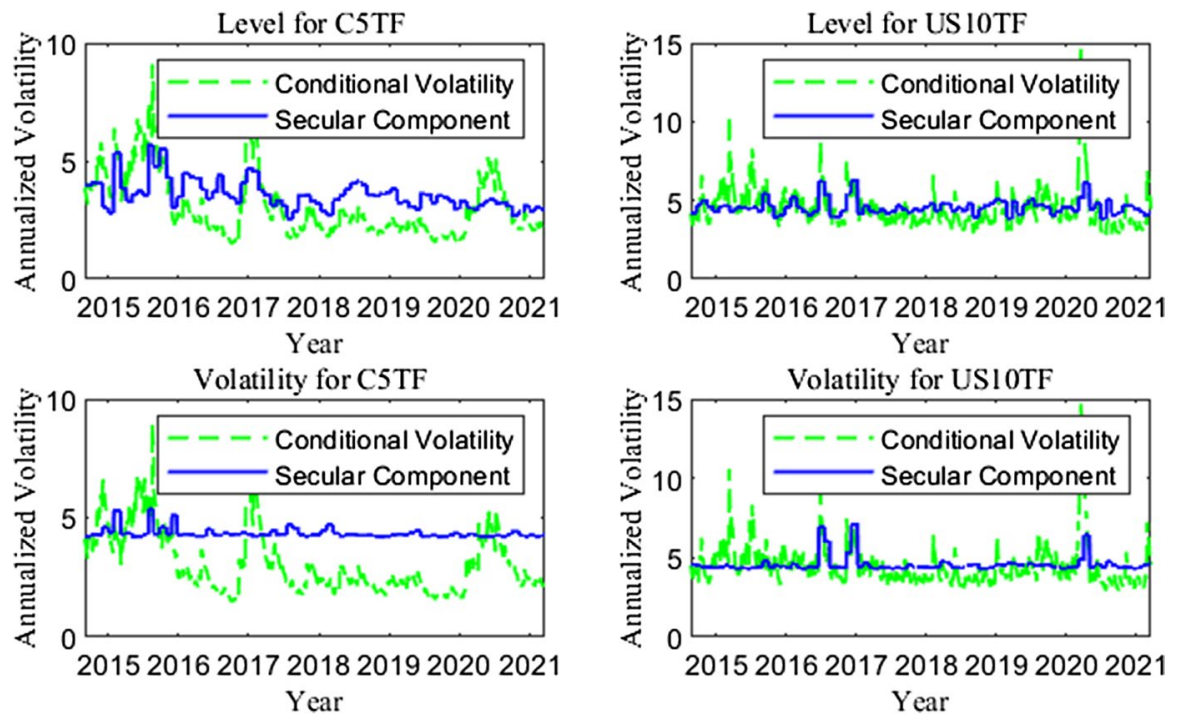

Fig. 4 GARCH-MIDAS with the level/volatility
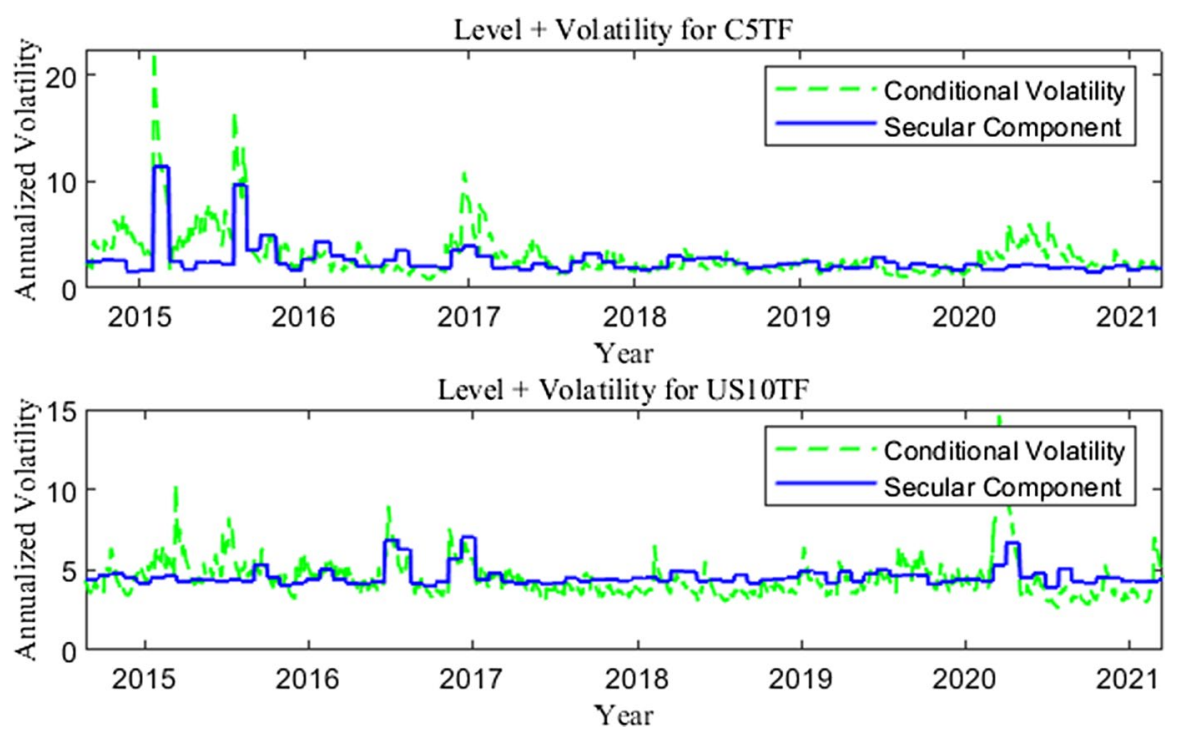

Fig. 5 GARCH-MIDAS with the level and volatility combined

See Fig. 4

The figure pertains the one-sided EPU level/volatility GARCH-MIDAS models for the conditional volatility and its long run component. The corresponding 
parameter estimates are shown in Table 4. The panel contains the time series paths of $\tau$ and $g * \tau$. They are all shown in standard deviation and annualized scale.

See Fig. 5

The figure pertains the one-sided EPU level and volatility combined GARCHMIDAS models for the conditional volatility and its long run component. The corresponding parameter estimates are shown in Table 4 . The panel contains the time series paths of $\tau$ and $g * \tau$. They are all shown in standard deviation and annualized scale.

Acknowledgement This work was supported by National Natural Science Foundation of China (Nos.71961004, 72061007, 71461005)

\section{Declarations}

Conflict of interest The authors declare that they have no conflict of interest.

\section{References}

Cox R A K, Mitchell J. The Intraday Volatility of U.S. Treasury futures. Review of Futures Markets, 1993, 12:29-54.

Brandt, M. W., \& Kavajecz, K. A. (2004). Price discovery in the US Treasury market: The impact of orderflow and liquidity on the yield curve. J Finance, 59(6), 2623-2654.

Man, K., Wang, J., \& Wu, C. (2013). Price discovery in the US treasury market: Automation vs intermediation. Manag Sci, 59(3), 695-714.

Orlowski, L. T. (2015). From pit to electronic trading: Impact on price volatility of US Treasury futures. Rev Financial Econ, 25, 3-9.

Fang, L., Yu, H., \& Li, L. (2017). The effect of economic policy uncertainty on the long-term correlation between US stock and bond markets. Econ Model, 66, 139-145.

Baker, S., Bloom, N., \& Davis, S. (2016). Measuring economic policy uncertainty. Quarter J Econ, 31(4), 1593-1636.

Bollerslev, T. (1986). Generalized autoregressive conditional heteroskedasticity. J Econometr, 31(3), 307-327.

Brandt, M. W., Kavajecz, K. A., \& Underwood, S. E. (2007). Price discovery in the treasury futures market. $J$ Futures Markets, 27(11), 1021-1051.

Ederington, L., \& Lee, J. (1993). How markets process information: news releases and volatility. J Finance, 48(4), 1161-1191.

Engle, R. F. (1982). Autoregressive conditional heteroscedasticity with estimates of the variance of United Kingdom Inflation. Econometrica, 50(4), 987-1007.

Engle, R. F., Ghysels, E., \& Sohn, B. (2013). Stock Market volatility and macroeconomic fundamentals. Rev Econ Stat, 95(3), 776-797.

Engle, R. F., \& Rangel, J. G. (2008). The Spline-GARCH model for low-frequency volatility and its global macroeconomic causes. Rev Financ Studies, 21(3), 1187-1222.

Ghysels, E., Santa-Clara, P., \& Valkanov, R. (2006). Predicting volatility: getting the most out of return data sampled at different frequencies. J Econometric, 131(1), 59-95.

Ghysels, E., Sinko, A., \& Valkanov, R. (2007). MIDAS regressions: further results and new directions. Econometric Rev, 26(1), 53-90.

Gulen, H., \& Ion, M. (2016). Policy uncertainty and corporate investment. Rev Finan Studies, 29(3), 523-564.

Hung, M. W., \& Zhang, H. (1995). Price Movements and price discovery in the municipal bond index and the index futures markets[J]. J Futures Markets, 15(4), 489-506.

Jonathan, B., \& Andrew, D. (2015). The asset pricing implications of government economic policy uncertainty. Manag Sci, 61(6), 3-18.

Mizrach, B., \& Neely, C. J. (2008). Information shares in the US treasury market [J]. J Banking Finan, 32(7), 1221-1233. 
Park, C. Y., Jro, R. M., Choi, J., \& Lim, H. (2017). Price Discovery and foreign participation in Korea's government bond futures and cash markets. J Futures Markets, 37(1), 23-51.

Schwert, G. W. (1989). Why does stock market volatility change over time? J Finan, 44, 1207-1239.

Shi, W. H., Eisenberg, L., \& Lee, C. (2009). Intraday Patterns, announcement effects, and volatility persistence in the japanese government bond futures market. Rev Pacific Basin Finan Markets Policies, 12(1), 63-85.

Wisniewski, T. P., \& Lambe, B. J. (2015). Does economic policy uncertainty drive CDS spreads? Int Rev Finan Anal, 42, 447-458.

Publisher's Note Springer Nature remains neutral with regard to jurisdictional claims in published maps and institutional affiliations. 